\title{
Importance of Journalism and Mass Communication for Nuclear Emergency Management
}

Tanja Perko*

Department of Political Science, University of Antwerp, Belgium

It has become clear from the lessons identified and, unfortunately, not well learnt from past nuclear and radiological events, communication is one of the most important challenges of emergency management [1-3]. The nuclear accident in Fukushima (Japan) in 2011 has once more emphasized the need to better understand how riskrelated messages are processed and how the public receives and accepts messages, related to protective actions in nuclear emergencies [4,5]. For instance, it is well known that one possible protective measure in case of a nuclear emergency is to take stable iodine tablets. What happened in Japan was that quite some people actually swallowed gargling agents containing povidone-iodine as a substitute for stable iodide tablets, an action which can actually be quite detrimental to someone's health [4].

Efficient communication about nuclear risks requires thorough insight into the factors that influence people's attentiveness and recall of information and, more generally speaking, the process of opinion formation related to possible recommendations. Furthermore, it is of great importance to comprehend the principles of media reporting about the nuclear emergency, since most information related to nuclear risks is not directly experienced, but rather learned through the mass media.

In general, communication research in the nuclear field, and especially opinion formation, has been approached either by social scientists or by nuclear experts. In academic research, only a limited number of such studies can be found. These mainly address risk communication and opinion formation in general, with the nuclear field being taken only as a case-study, thus without taking into account any of its specificity. On the other hand, researchers coming from the nuclear field who study communication don't tend to apply the strict scientific standards that they are used to in their natural science experiments. Their research on communication is therefore lacking in scientific protocols and methodology, as they are not familiar with the field of social sciences. In other words, the limitations of the existing knowledge may be explained by a lack of integration of different disciplines.

Yet, the research in this field should be inherently interdisciplinary, as it embodies several research domains: mass media, risk communication, risk perception, emergency management, radiation protection, and finally, opinion formation. An integrative approach is needed in order to understand radiation risks, how people acquire information from mass media and form an opinion about these risks, how they make decisions about them and how the media translate the information provided by experts and/or risk managers.

Therefore, the research of mass media and journalism has to use an interdisciplinary approach and it has to adapt and synthesize concepts and theoretical models stemming from a number of fields: 1) lessons learned from the field of radiation protection and nuclear emergency management $[6,7] ; 2)$ systematic and heuristic-based information processing models [8-10], 3) the theory of risk research, [11-13], and 4) research on media content [14-16]. The first provides the specific context of nuclear emergency management, the second helps to understand how people acquire information from elites and the mass media and convert it into preferences, the third is useful in determining the factors which may ultimately affect an individual's risk-related opinion and the last explores the mass media as the main source of information related to nuclear emergency events.

This editorial encourages the researchers to focus on risk communication in nuclear emergency management and in particular on three different aspects: firstly, the reception and acceptance of information provided by mass communication. Secondly, it encourages the researchers to explore the influence of people's prior knowledge on the acceptance of communicated messages and the perception of the communicated risks. Lastly, the media coverage of nuclear emergency events needs to be investigated and analyzed by strict scientific roles of media content and discourse analysis.

It is important to note that nuclear emergency management is structured in three phases: preparedness, response and recovery. Thus, different types of communications are applied, with different levels of media attention-depending on the specific phase. Different case studies can be used to analyze preparedness communication, crisis communication and long-term communication for recovery. The main objective is an attempt to bring different

information processing models and different disciplines together in order to get insight into the perception of radiation risks and the information processing of nuclear emergency communication in different contexts.

Risk communication in the nuclear field may have several aims: 1) to warn people in case of a nuclear emergency [17],2) to inform about radiation risks $[6,18], 3)$ to prevent panic and outrage [19], 4) to support the stakeholders to make informed decisions related to radiation risks [20], and 5) to establish two-way communication and joint problem solving. Since human behaviour is primarily driven by perception and not by facts [11], risk perception is a concept of great importance when developing sound and successful risk communication. In general, communication in the nuclear field is transferred mainly by mass media.

The results from previous studies on mass media and nuclear emergencies support the conclusion that the magnitude and the probability of a nuclear event seem to play only a minor role in the media coverage of nuclear emergencies $[21,22]$. The media are not mere

*Corresponding author: Tanja Perko, Department of Political Science, University of Antwerp, Belgium, Tel: +322655759/+3214332851; E-mail: tperko@SCKCEN.BE

Received August 07, 2012; Accepted August 08, 2012; Published August 09, 2012

Citation: Perko T (2012) Importance of Journalism and Mass Communication for Nuclear Emergency Management. J Mass Commun Journalism 2:e127. doi:10.4172/2165-7912.1000e127

Copyright: () 2012 Perko T. This is an open-access article distributed under the terms of the Creative Commons Attribution License, which permits unrestricted use, distribution, and reproduction in any medium, provided the original author and source are credited. 
Citation: Perko T (2012) Importance of Journalism and Mass Communication for Nuclear Emergency Management. J Mass Commun Journalism 2:e127. doi:10.4172/2165-7912.1000e127

transmitters of the nuclear event, but they report also on the nuclear emergency management and other issues that are of concern for the society, for instance the future of nuclear energy in the country [21]. It seems that media construct the reality of a nuclear event. In general, the media coverage of nuclear emergences reflects the organizational rules, the external expectations - for instance public opinion and the memory of the past nuclear experiences (including accidents). The political salience of the issue dominates the transformation process related to nuclear emergency management and influences media reporting. The degree of social (political) conflict related to the nuclear energy program correlates strongly with media coverage. The media content related to nuclear events (either minor event or nuclear accident) is a mix of original messages describing the event and re-coded messages (e.g. the health effects of the event as estimated by different experts). Thus, media leave it to the final receiver (affected population or general population) to understand what is the original information and what is the broader framework hinted at by various (other) transmitters reported in the media. These other transmitters were revealed to be politicians, pressure groups, independent researchers or independent experts [22]. Signals relating to conflicts, disagreements and contradicting information between the different sources of information are intensified in media reporting about nuclear events [23]

To conclude. What lessons can be drawn from investigating the information provided to the public by the mass media in a case of a nuclear emergency? The research in mass media reporting on a nuclear event can be beneficial for nuclear emergency management in two major aspects. On the one hand, such an analysis shows how to deliver risk messages effectively through the mass media and, on the other hand, it brings insight into the information that has to be communicated to the mass media in order to prevent a public health in a case of an nuclear emergency, like for instance Fukushima nuclear accident.

\section{References}

1. Abbott PC, Wallace, Beck M (2006) Chernobyl: Living with Risk and Uncertainty Health Risk \& Society 8: 105-121.

2. Boiarsky C (2004) Avoiding disasters with better communication in 51st Annual Conference of the Society-for-Technical-Communication. Baltimore, MD: Soc. Technical Communication 387-391.

3. Covello VT (2011) Risk Communication, Radiation, and Radiological Emergencies: strategies, tools, and techniques. Health Phys 101: 511-530.

4. Kanda RS, Tsuji S, Yonehara H (2012) Perceived Risk of Nuclear Power and Other Risks During the Last 25 Years in Japan. Health Phys 102: 384-390.

5. Ropeik D (2011) Poor Risk Communication In Japan Makes the Fear Much Worse. In Psychologiy Today.

6. IAEA (2006) Manual for first Responders to a Radiological Emergency in Emergency Preparedness and Response, edited by International Atomic Energy Agency. Vienna.

7. Sohier A (2002) A European Manual for OFF-site Emergency Planning and Response to Nuclear Accidents. Belgian Nuclear Research Centre, SCK CEN 339

8. Cacioppo JT, Petty ER (1984) The Elaboration Likelihood Model of Persuassion. Dvances in Consumer Research Volume 11: 673-675.

9. Trumbo WC (2002) Information Processing and Risk Perception: An Adaption of the Heuristic-Systematic Model. Journal of Communication 52: 367-382

10. Zaller J (2006) The Nature and Origins of Mass Opinion. New York: Cambridge university press.

11. Renn O (2008) Risk Governance; Coping with Uncertainty in a Complex World London: Earthscan.

12. Sjöberg L (2000) Factors in risk perception. Risk Analysis 20: 1-11.
13. Slovic P, Finucane ML, Peters E, MacGregor DG (2004) Risk as analysis and risk as feelings: Some thoughts about affect, reason, risk, and rationality. Risk Anal 24: 311-322.

14. Gamson, William A, Modigliani A (1989) Media discourse and public opinion on nuclear power: a constructionist approach. The American Journal of Sociology 95: 1-37.

15. Neuendorff KA (2002) The Content Analysis Gueidebook. Thusand Oaks, California: Sage Publication.

16. Vasterman, Peter (2005) Media-Hype Self-reinforcing News Waves. Journalistic Standards and the Construction of Social Problems. European Journal of Communication 20: 508-530

17. IAEA (2012) Communication with the Public in a Nuclear or Radiologica Emergency. Vienna: EPR-Public Communications, IAEA.

18. Rojas-Palma C, Liland A, Jerstad AN, Etherington G, Perez MR, et al. (2009) TMT Handbook; Triage, Monitoring and Treatment of people exposed to ionising radiation following malevolent act. Norway: Lobo Media AS.

19. Sandman PM (1987) Risk Communication: Facing Public Outrage Environmental Protection Agency Journal 13: 21-22.

20. Renn O (2004) The role of stakeholder involvement in risk communication. AtwInternational Journal for Nuclear Power 49: 602

21. Cantone MC, Sturloni G, Brunelli G (2007) The Role Played by Stakeholders in the Public Debate that Brought Italy out of the Club of Nuclear Energy Producers. Health Physics 93: 261-266.

22. Perko T, Turcanu C, Carlé B, Vidmar T (2011) How transparent is transparen enough? A case study of a minor nuclear event. In Nuclear Energy-Global Trends and Perspectives in South-East Europe, edited by K. Terzic. Podgorica, Montenegro.

23. Cantone, Marie C, Perko T, Catrinel T, Iztok P et al. (2012) Content analysis of the media reporting on the Fukushima nuclear accident in three European countries. In 13th International Congress of the International Radiation Protection Association Glasgow, United Kingdom. 